\title{
AC conductivity of binary silver phosphate glasses
}

\begin{abstract}
Samples of binary silver phosphate glasses with composition $(\mathrm{Ag} 2 \mathrm{O}) \mathrm{x}(\mathrm{P} 2 \mathrm{O} 5) 1-\mathrm{x}$ have been prepared and their ac electrical conductivities measured over a range of frequency, composition and temperature. It is observed that a.c. conductivity increases very gradually at low frequency (below $1 \mathrm{kHz}$ ), but rapidly at higher frequency (above $10 \mathrm{kHz}$ ). Conductivity as high as 10-5 Scm-1 has been observed depending on the composition, frequency and temperature of the samples. It increases almost linearly with the mole fraction of Ag2O. As a function of temperature, the conductivity increases too with temperature. Arrhenius plot is obeyed and activation energy of 0.41 to $0.46 \mathrm{eV}$ has been obtained.
\end{abstract}

Keyword: AC conductivity; Binary silver phosphate glasses 